\title{
Técnicas Handmad: Uma coleção visando a sustentabilidade.
}

Fernanda Pelin Mion ${ }^{1}$;

Prof. Dr. Tomás Queiroz Ferreira Barata²;

\section{resumo:}

O presente artigo versa sobre algumas ações que estão acontecendo na área da moda, na busca por produtos e processos com cunho mais sustentável, seja através do processo produtivo ou da matériaprima. O fio de seda revela-se como uma ótima alternativa para a produção de peças handmade, desse modo a pesquisa abordou o desenvolvimento de produto visando uma produção que minimizasse os aspectos ambientais e focando no trabalho das artesãs da região Norte do Estado de Santa Catarina, estabelecendo uma valorização do produto entre a arte, a moda e as crocheteiras. A metodologia utilizada pauta-se em revisão bibliográfica e por meio de uma abordagem da pesquisa-ação. Como resultado identificou-se a importância do trabalho dessas artesãs na comunidade, favorecendo a troca de conhecimento, e também revelam os aspectos socioeconômicos relacionados a geração de renda através da comercialização da produção artesanal de peças de crochê movimentando o setor informal da economia local.

palavras-chave:

design de moda; design de superfície; crochê; comunidade; desenvolvimento de produto.

\footnotetext{
${ }^{1}$ http://lattes.cnpq.br/5889648480626125

2 http://lattes.cnpq.br/7865768257571169
} 


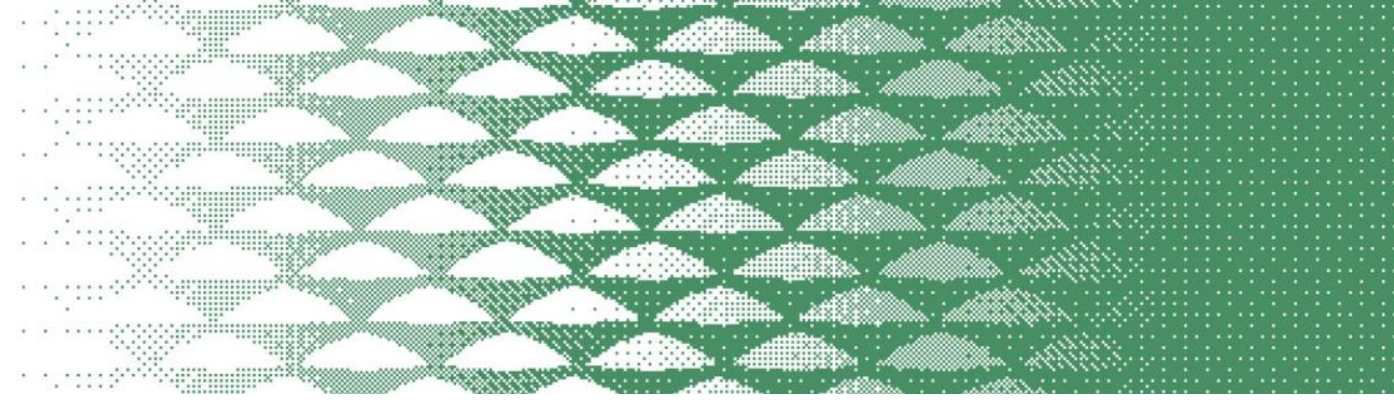

\section{Introdução}

A interdisciplinaridade se apresenta desde o início na história do Desenvolvimento Sustentável em que há uma variedade de conceitos provenientes de diversas disciplinas. O Design contemporâneo se apresenta cada vez mais implicado com os conceitos de Desenvolvimento Sustentável, inovação e bemestar social, principalmente diante as demandas da sociedade e do mercado. A análise e o design do ciclo de vida do sistema-produto são primordiais em qualquer desenvolvimento de projeto de produto ou serviço.

A indústria Têxtil e de vestuário é a segunda maior do mundo e também, é uma das mais poluentes. Esse setor, representa entre 2 e $10 \%$ do impacto ambiental da avaliação do ciclo de vida europeu, atingindo as categorias de produtos que causam maior impacto ambiental. Logo após, vem os setores de alimentos e bebidas, transportes e habitação (RANA et al., RESTA; DOTTI, 2015; KARUNAMOORTHY et al., 2015; NISAL et al., 2013).

Ao desenvolver um novo produto para o vestuário cabe ao designer estabelecer as relações que serão traçadas entre a superfície têxtil e o corpo que esta envolverá. É por meio dos processos de moulagem, crochê, tingimento, entre outros, que o fio de seda se transforma em vestimenta e assume caráter tridimensional ao envolver o corpo. Desta maneira, o Design de Superfície que leva em consideração o produto ao qual se destina pode auxiliar no processo de transformação do crochê em vestuário

Partindo de tal perspectiva de consumo consciente, apresenta-se nesse artigo a sustentabilidade por meio do movimento produtos desenvolvido a partir do artesanato, voltado para a relação entre indivíduo e objeto, e a criação agregada a valores culturais. Para tanto, é desenvolvido um estudo teórico acerca da produção lenta e como ela pode ser aplicada no ramo do artesanato. Nesta perspectiva, a valorização do produto, matéria-prima e a preocupação com o meio ambiente é abordada no decorrer deste artigo, apresentando técnicas manuais de intervenções no design de superfície, tingimento natural e desenvolvendo um produto com artesãs de uma comunidade da cidade de São Francisco do Sul - SC.

\section{Design de Moda, Sustentabilidade e Ecodesign}

A importância de se trabalhar com o Ecodesign em uma coleção, está crescendo cada vez mais nas empresas e a atuação do design tem se expandido. Não se trata mais de se articular somente um conjunto de elementos tangíveis, mas um conjunto de ideologias, crenças, valores, assim como um agregado de serviços que permitirão ao consumidor a satisfação de suas necessidades e desejos.

O conceito de desenvolvimento sustentável aparece pela primeira vez em 1987, definido pela Comissão Mundial para o Ambiente pela ONU, sob direção de Gro Harlem Brundtland como "aquele que satisfaz as necessidades do presente sem comprometer a capacidade das futuras gerações de satisfazer suas próprias necessidades". (BRIAN, 2008, p.20).

O produto visto como sistema é um ponto crucial para se compreender, estudar e analisar o seu ciclo de vida, o qual "é interpretado em relação aos fluxos - de matéria, energia e emissão - das atividades que o acompanham em toda a sua vida". (MANZINI; VEZZOLI, 2002, p.91). O ciclo de vida de um produto pode ser compreendido como um conjunto de processos reagrupados de acordo com Manzini e Vezzoli (2002, p.91) em: pré-produção; produção; distribuição; uso; descarte.

O Ecodesign que teve sua primeira definição dada por Victor Papaneck trabalha em prol de diminuir o impacto do ser humano no planeta. Para Kazazian (2005, p.36), o ecodesign faz parte de um processo que busca tornar a economia mais "leve", sendo chamado também de ecoconcepção que trata da redução do impacto de um produto no meio, conservando suas qualidades de uso (funcionalidade, desempenho) para melhorar a qualidade de vida dos usuários. "Segundo essa abordagem, o meio 


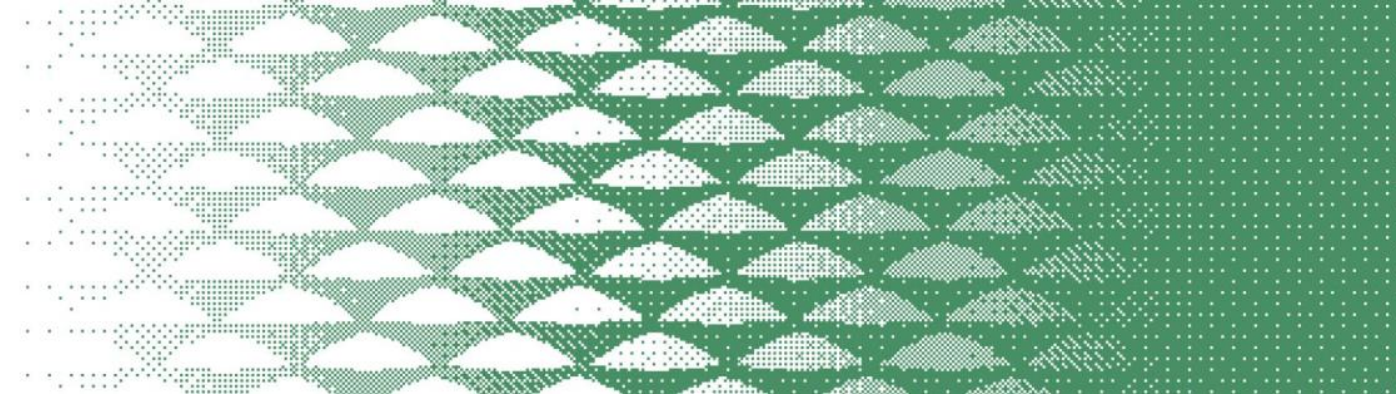

ambiente é tão importante quanto à exequibilidade técnica, o controle dos custos e a demanda do mercado" (Kazazian, 2005, p.36). O ecodesign, como uma abordagem global, exige uma nova maneira de conceber o desenvolvimento de novos produtos, considerando todas as etapas do ciclo de vida de um ciclo de produto ou serviço. Ressalta-se que em uma ecoconcepção inicia-se um processo cooperativo com uma cadeia de atores em uma abordagem transversal e multidisciplinar.

\section{Handmade e Crochê}

A tradução literal da palavra inglesa handmade é "feito à mão", ou seja, o produto todo ou sua maior porção é realizado através do trabalho manual de seu criador. Atualmente, o modo como um produto é fabricado e as técnicas utilizadas para concluí-lo são características cada vez mais apreciadas pelos consumidores que prezam pela compra consciente e pela possibilidade de criar laços emocionais atemporais com a peça adquirida.

Os primeiros registros documentados e escritos sobre a técnica do crochê datam do século XIX, por volta de 1830. Potter (1990) acredita que o crochê como se conhece hoje surge do resultado de diferentes experimentações com trabalhos em agulha. Porém a autora Potter (1990) completa que essas não são as primeiras manifestações e experimentações de laçadas próximas a aparência do crochê, pois há registros de têxteis com essas características datadas de épocas mais remotas que o século XIX.

A prática do crochê segue tendo grande repercussão social. Com uma agulha e um novelo de linha, é possível tecer um universo riquíssimo de padrões, que são produzidos graças à facilidade de aplicação de três pontos básicos.

\section{A matéria-prima: Seda e a Pegada de Carbono}

A cadeia têxtil e de confecção é constituída por grandes setores industriais, como a fiação, tecelagem, beneficiamento e confecção, assim como o comércio. Tais seguimentos possuem papel importante na economia dos países em desenvolvimento, pois proporcionam grande absorção de mão-de-obra, gerando renda e receita para o país (COSTA; ROCHA, 2009; SILVA, 2009).

A sericicultura apresenta baixo impacto ambiental, contribui com a diminuição do êxodo rural e possui significativa importância econômica, o que a qualifica como uma das atividades ideais para o incremento da economia nacional, uma vez que é praticada como uma indústria subsidiária da agricultura (MENEGUIM et al., 2007; SANTOS et al., 2011).

A fibra de seda é comumente utilizada para a fabricação de artefatos têxteis, mas apresenta características que possibilitam sua aplicabilidade em diversos outros campos, que vão desde artesanato, utilizando os subprodutos da indústria convencional de fiação, às aplicações médicas e outras (BABU, 2012).

De acordo com a World Wildlife Fund (WWF) (2016), a Pegada de Carbono da humanidade é a principal causa das mudanças climáticas, devido ao fato de gerarmos emissões de dióxido de carbono mais rápido do que podemos absorver. Desde 1970, a humanidade triplicou a Pegada de Carbono total. No entanto, sua redução é um passo essencial para acabar com o abuso ecológico e conter mudanças climáticas.

A produção de amoreira é o ponto de partida para a sericultura ${ }^{3}$. Ela apresenta um crescimento rápido e começa a produzir quantidades substanciais de folhas, para a criação do bicho-da-seda, após um ano de plantação (ASTUDILLO et al., 2016). Srikantaswamy e Bindroo (20140), argumentam que a produção de biomassa de amoreira tem qualidade atraentes para sequestrar carbono, devido ao seu rápido

\footnotetext{
${ }^{3}$ Sericicultura, ou sericultura, stricto sensu, é a parte da Zootecnia que trata do estudo e da criação do lepidóptero Bombyx mori, o bicho-da-seda.
} 


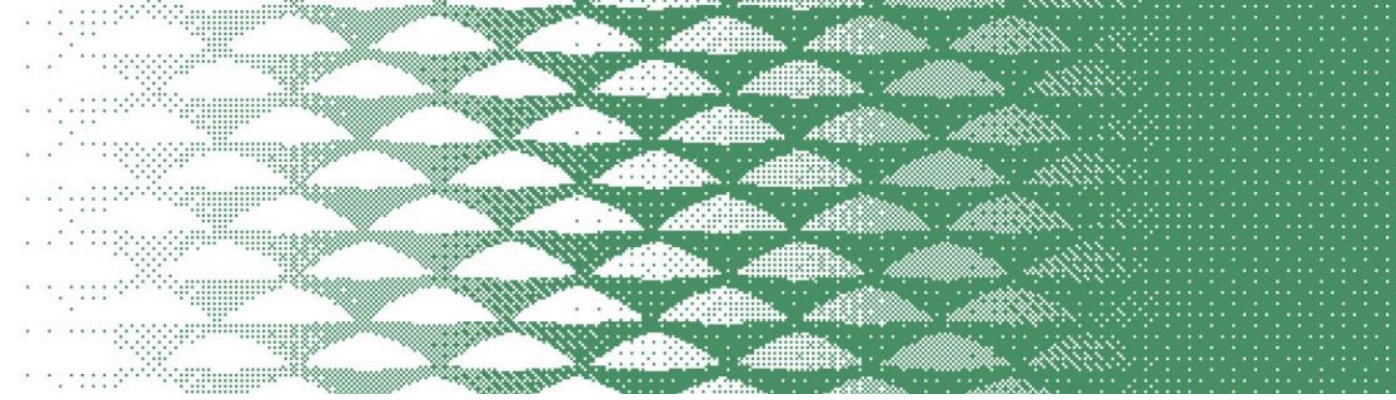

O trabalho das artesãs traz independência financeira, por meio da comercialização do artesanato que produzem. Ganhar o próprio dinheiro com o oficio que exercem dá ao grupo empoderamento diante a sociedade, fazendo com o que o trabalho dessas artesãs sejam reconhecidas e valorizadas;

Das desvantagens levantadas, a principal e a mais evidente é o tempo de produção para cada peça a ser produzida, pois para chegar ao resultado do vestido da imagem 2 , foram quase 20 dias de trabalho. Desta forma, fica em aberto para as possibilidades de melhorias no processo artesanal com o objetivo de diminuir o tempo de execução em cada peça.

Ainda sobre as desvantagens, infelizmente, uma grande quantidade de materiais têxteis não pode ser tingida com corantes naturais por si só, isso gera uma baixa capacidade de produção em série. Assim, o uso de corantes sintéticos pode também ser usado, porém, uma porção do tingimento de têxteis pode ser complementada por corantes naturais ecologicamente seguros, em geral, o processo e o uso pouco otimizado da quantidade de corante, gera uma larga quantidade de resíduos que devem ser tratados antes de seu despejo.

\section{Considerações Finais}

As superfícies têxteis são base para um produto de vestuário. Investigar processos do tecimento com as agulhas é uma maneira de ampliar a perspectiva do desenvolvimento de novos produtos de moda. Sendo assim, esse artigo abordou a relação entre o design de moda, o design de superfície, abordando a sustentabilidade no processo do desenvolvimento e o crochê aplicando essas especialidades, discutindo não apenas conceitos e processos, mas também proporcionando a história do artesanato local.

Esse estudo proporcionam uma visão diferente de uma técnica de fazer manual recorrente ao ambiente popular. Contudo, como designers, devemos sempre buscar uma visão global, obtendo novas propostas e novas possibilidades projetuais, de maneira a envolver questões técnicas e simbólicas dentro dessa abordagem. As descobertas desta pesquisa definiram um processo metodológico e replicável na obtenção de novos produtos artesanais.

Estas novas informações, se pesquisadas e reunidas, poderiam ser utilizadas para desenvolvimentos de novos projetos, contudo, buscar o apoio dos órgãos governamentais e locais, uma vez que seus resultados se manifestam diretamente na própria construção da cidadania e da economia local valorizando o trabalho das artesãs visando a geração de renda em novas comunidades.

\section{Handmad Techniques: A collection aimed at sustainability.}

Abstract: This article is about some actions that are taking place in the fashion area, in the search for more sustainable products and processes, whether through the production process or raw material. Silk thread reveals itself as a great alternative for the production of handmade pieces, thus the research approached the development of a technical product, a production that would minimize environmental aspects and focusing on the work of artisans in the northern region of the state of Santa Catarina, establishing an appreciation of the product between art, fashion and crocheters. The methodology used in literature review and through an action research approach. As a result, the importance of the work of these artisans in the community was identified, favoring the exchange of knowledge, and also reveal the socioeconomic aspects related to income generation through the commercialization of the artisanal production of crochet pieces, moving the informal sector of the local economy.

Keywords: fashion design; surface design; crochet; community; product development. 


\section{Referências bibliográficas}

BABU, K. M. Silk Fibres. Handbook of natural fibres, v.2, p. 146-170. Processing and applications. 2012.

BRIAN, Edwards. O guia básico para a sustentabilidade. Barcelona: Gráficas 92, 2008.

COSTA, A. C. R.; ROCHA, E. R. P. Panorama da cadeia produtiva têxtil e de confecção e a questão da inovação. BNDES Setorial (Rio de Janeiro), n.29, p. 159- 202, 2009.

DAS, S. Fibres and fabrics used in home textiles. In: Performance of home textiles. Woodhead Publishing Limited. p. 22-41. 2010a.

DUBURG, Annette. Moulage: arte e técnica no design de moda/Annette Duburg, Rixt van der Tol ; tradução: Bruna Pacheco. - Porto Alegre : Bookman, 2012.

GONÇALVES, M. J.; SAAR, J. H.; SOUZA, A. A. U.; SOUZA, S. M. A. G. U. Descoloração Biológica de Efluentes Têxteis: Um processo ecologicamente correto para a remoção de corantes azóicos. Química Têxtil, São Paulo, n. 90, p. 70, mar. 2008.

MANZINI, E.. Design para a inovação social e sustentabilidade: Comunidades criativas, organizações colaborativas e novas redes projetuais. Cadernos do Grupo de Altos Estudos. Rio de Janeiro: E-papers, v.1, 2008.

MANZIN, Ezio. Vazzoli, Carlos. 0 desenvolvimento de produtos sustentáveis. Os requisitos ambientais dos produtos industriais. São Paulo. Editora da Universidade de São Paulo. 2008.

MENEGUIM, A. M.; LOVATO, L.; DA SILVA, R. Z.; YAMAOKA, R. S.; NAGASHIMA, G.T.; PASINI, A. Influência de cultivares da Amoreira Morus spp. Sobre a produção e qualidade de casulos de bicho-da-seda, Bombyx mori L. (lepidóptera: Bombycidae). Ecology, Behavior and Bionomics. p. 670674. 2007

NEEDLES, H. L. Textile fibers, dyes, finishes and processes: A concise guide. Davis: University of California, 1986.

OLIVEIRA, Lisandra. Artesanato se transforma em geração de renda para mulheres em São Francisco Sul. NSC Total, Blumenau, 25, fev. 2019. Disponível em:

https://www.nsctotal.com.br/colunistas/lisandra-oliveira/artesanato-se-transforma-em-geracao-derenda-para-mulheres-em-sao. Acesso em: 18, mai e 2021.

PETERS, G.; SVANSTROM, M.; ROSS, S.; SANDIN, G.; ZAMANI, B. Carbon footprints in the textile industry. In: Handbook of Life Cycle Assessment (LCA) of Textiles and Clothing. 1 st ed. The Textile Institute. Elsevier. p. 3-30. 2015.

POTTER, Annie Louise. A Living Mystery: The International Art \& History of Crochet. Estados Unidos: Editora, 1990

KAZAZIAN, T. Haverá a idade das coisas leves: design e desenvolvimento sustentável, São Paulo: Ed. SENAC, 2005.

TAMBORRINI, P.. Design de inovação. Do design ao design de sistemas: objetos, relações e comportamento. In: Cadernos de Estudos Avançados em Design: inovação / organização: Dijon De Moraes, Itiro Iida, Regina Álvares Dias - Barbacena: EdUEMG, p. 53-63, 2012.

RANA, S.; PICHANDI, S.; KARUNAMOORTHY, S.; BHATTACHARYYA, A.; PARVEEN, S.; FANGUEIRO, R. Carbon Footprint of Textile and Clothing Products. In: Handbook of Sustainable Apparel Production. CRC Press, p. 141-165. 2015. 
RIBEIRO, V. A. S. Fotodegradação de efluentes têxteis catalisada por ZnO. 2010. 128 f. Dissertação (Mestrado) - Programa de Pós-Graduação em Engenharia Química, Universidade Estadual de Maringá, Maringá, 2010.

SAMANTA, A. K.; KONAR, A. Dyeing of Textiles with Natural Dyes. In: KUMBASAR, E. P. A. Natural Dyes. Croácia: Intech, p. 29-56, 2011. 